\title{
Clinical Stage IIA Gastric Cancer AJCC v8
}

National Cancer Institute

\section{Source}

National Cancer Institute. Clinical Stage IIA Gastric Cancer A/CC v8. NCI Thesaurus. Code C133681.

Stage IIA includes: (T1, N1, N2, or N3, M0); (T2, N1, N2, or N3, M0). T1: Tumor invades the lamina propria, muscularis mucosae, or submucosa. T2: Tumor invades the muscularis propria. N1: Tumor with metastasis in one or two regional lymph nodes. N2: Tumor with metastasis in three to six regional lymph nodes. N3: Tumor with metastasis in seven or more regional lymph nodes. M0: No distant metastasis. (AJCC 8th ed.) 